Tropical Journal of Pharmaceutical Research January 2017; 16 (1): 83-89

ISSN: $1596-5996$ (print); 1596-9827 (electronic)

(C) Pharmacotherapy Group, Faculty of Pharmacy, University of Benin, Benin City, 300001 Nigeria.

All rights reserved.

Available online at http://www.tjpr.org

Original Research Article

http://dx.doi.org/10.4314/tjpr.v16i1.11

\title{
Anti-tumor effect of polysaccharides isolated from Taraxacum mongolicum Hand-Mazz on MCF-7 human breast cancer cells
}

\author{
Hu Niu ${ }^{1,2}$, JunWei Fan ${ }^{3}$, GangPu Wang ${ }^{2}$, Jian Wang ${ }^{2}$, YanBiao $\mathrm{Chu}^{4}$, QiFeng \\ Yang $^{6 *}$, LinBo Wang ${ }^{7}$ and Bin Tian ${ }^{5}$ \\ ${ }^{1}$ Shandong University, Jinan 250013, ${ }^{2}$ Department of General Surgery, The Fourth People's Hospital of Jinan, Jinan 250031, \\ ${ }^{3}$ Department of general surgery, First People's Hospital of Qingdao Economic and Technological Development Zone, Qingdao \\ 266555, ${ }^{4}$ Department of Respiration, ${ }^{5}$ Department of Breast and Thyroid Surgery, Jinan Central Hospital Affiliated to Shandong \\ University, Jinan 250013, ${ }^{6}$ Department of Breast Surgery \& Pathology Tissue Bank, Qilu Hospital, Shandong University, Jinan \\ 250012, Shandong, ${ }^{7}$ Department of Oncology Surgery, Sir Run Run Shaw Hospital Affiliated to Zhejiang University, Hangzhou \\ 310020, Zhejiang, China
}

*For correspondence: Email: qifengyangbs@163.com; Tel: +86-0531-82169114

Received: 9 September 2016

Revised accepted: 22 December 2016

\begin{abstract}
Purpose: To optimize the extraction conditions for the ultrasound-assisted extraction of polysaccharides from T. mongolicum (PTM) and investigate their anti-tumor effect on human breast cancer MCF-7 cells.

Methods: To optimize the extraction conditions of PTM, response surface methodology (RSM) was performed. The effects of extraction temperature, liquid-solid ratio and extraction time on the yield of PTM were investigated using a Box-Behnken design (BBD). The in vitro anti-tumor effect of PTM on MCF-7 cells was investigated by methylthiazolyldiphenyl-tetrazolium bromide (MTT) assay, while the mechanism of PTM-induced apoptosis was assessed by evaluating the expressions of p53, Bax and $B C l-2$ proteins using western blot analysis. Furthermore, the in vivo anti-tumor effect of PTM on MCF-7 cells was studied in mice.

Results: The optimal conditions for the extraction of PTM were as follows: extraction temperature, 58.2 ${ }^{\circ} \mathrm{C}$; liquid-solid ratio, $15 \mathrm{~mL} / \mathrm{g}$; and extraction time, $44.12 \mathrm{~min}$. Under these optimal conditions, the yield of PTM was $4.84 \pm 0.13 \%$. PTM showed significant anti-tumor effect on MCF-7 cells in vitro. The expressions of pro-apoptotic proteins, p53 and Bax, were significantly upregulated $(p<0.05)$, while the expression of anti-apoptotic protein, Bcl-2, was significantly down-regulated $(p<0.05)$ after treatment with PTM. PTM also showed significant inhibitory effect $(p<0.05)$ on MCF-7 cells in vivo in a dosedependent manner.

Conclusion: RSM is effective in optimizing the extraction conditions of PTM by ultrasonic extraction. PTM possesses significant anti-tumor effect on MCF-7 human breast cancer cells, both in vitro and in vivo.
\end{abstract}

Keywords: Polysaccharides, Taraxacum mongolicum, Human breast cancer, MCF-7 cells, Apoptosis, Box-Behnken design, Response surface methodology

Tropical Journal of Pharmaceutical Research is indexed by Science Citation Index (SciSearch), Scopus, International Pharmaceutical Abstract, Chemical Abstracts, Embase, Index Copernicus, EBSCO, African Index Medicus, JournalSeek, Journal Citation Reports/Science Edition, Directory of Open Access Journals (DOAJ), African Journal Online, Bioline International, Open-J-Gate and Pharmacy Abstracts

\section{INTRODUCTION}

Although diagnosis and treatment have been improved, breast cancer still remains the second leading cause of cancer-related death in women worldwide [1]. Currently, breast cancer is the most common cancer among women in China, and approximately $0.03 \%$ women will develop 
breast cancer in their lifetime, and the proportion is rising as this disease becomes more and more common in younger patients [2,3]. However, the conventional treatments (chemotherapy and radiation) have harmful side effects $[4,5]$. Thus, it is very necessary to develop new effective drugs for the treatment of breast cancer.

Recently, more and more polysaccharides from natural plants have been proved to have various biological activities. More importantly, a growing amount of researches have shown that polysaccharides could resist tumors by inducing tumor apoptosis [6,7]. Taraxacum mongolicum Hand.-Mazz., a member of genus Taraxacum, is a folk medicine which was used to treat viral infectious diseases and inflammatory disorders, etc. [8]. Furthermore, T. mongolicum has gained wide attention because of its favorable therapeutic effect for many diseases, especially jaundice gonorrhoea, pneumonia and mastopathy $[8,9]$. However, there have been few reports regarding the anti-tumor effect of polysaccharides extracted from $T$. mongolicum on breast cancer. Therefore, the present study was aimed to investigate the optimum extraction of polysaccharides from T. mongolicum (PTM) and explore their anti-tumor effect on breast cancer.

\section{EXPERIMENTAL}

\section{Chemicals and reagents}

Methylthiazolyldiphenyl-tetrazolium bromide (MTT) was obtained from Sigma Chemical (St. Louis, MO, USA). Minimum Essential Medium (MEM) was obtained from Gibco (Grand Island, NY, USA). p53, Bcl-2, Bax, $\beta$-actin monoclonal primary antibodies and horseradish peroxidaseconjugated secondary antibodies were purchased from Santa Cruz Biotechnology (Santa Cruz, CA, USA). All the other reagents and chemicals used in the experiment were of analytical grade.

\section{The preparation of PTM}

The whole plant of $T$. mongolicum was purchased from the Traditional Chinese Medicine Market of Nanyang (Nanyang, China), and authenticated by the Department of Traditional Chinese Medicine in Qilu Hospital (Jinan, China). The voucher specimen (FTCM no. 20160321) was deposited in the hospital herbarium of Qilu Hospital. The powder of dried whole plant of $T$. mongolicum $(10 \mathrm{~g})$ was put into conical flask with stopper, and then extracted by an AS3120A ultrasonic device (Tianjin Automatic Science Instrument Co., Ltd, Tianjin, China) with designed extraction time (30, 40 and $50 \mathrm{~min}$ ), liquid-solid ratio $(6,12$ and $18 \mathrm{~mL} / \mathrm{g})$ and extraction temperature $\left(40,50\right.$ and $\left.60^{\circ} \mathrm{C}\right)$. After extraction, the solutions were concentrated under reduced pressure to $20 \mathrm{~mL}$ by a rotary evaporator. The concentrated solutions were mixed with anhydrous ethanol (1:3, v/v) and left overnight at $4{ }^{\circ} \mathrm{C}$. Then the precipitates were obtained by centrifugation at 5000 rpm for 10 min, and washed respectively with anhydrous ethanol and acetone. Finally, the precipitates were dried to a constant weight at $45^{\circ} \mathrm{C}$. The extraction yield (\%) was calculated as in Eq 1.

$Y(\%)=\left(W_{1} / W_{0}\right) 100$

where $\mathrm{Y}$ is the yield of polysaccharides extracted from $T$. mongolicum, $\mathrm{W}_{1}$ is the weight of polysaccharides extracted from $T$. mongolicum $(\mathrm{g})$, and $\mathrm{W}_{0}$ is the weight of the dried powder of T. mongolicum (g).

\section{Experimental design of RSM}

Design-Expert trial version 8.0.5 software (StatEase Inc., Minneapolis, USA) was used to analyze the experimental data. To determine the optimal levels for extraction conditions of extraction temperature, liquid-solid ratio and extraction time, a Box-Behnken design (BBD) (three-level and three factors) was applied. As shown in Table 1, the complete experimental design carried out in random order, and was consisted of 17 experimental points.

\section{Cell culture}

MCF-7 human breast cancer cells were purchased from American Type Culture Collection (ATCC) (Manassas, VA, USA). Cells were cultured in MEM supplemented with $10 \%$ fetal bovine serum (FBS), streptomycin (100 $\mu \mathrm{g} / \mathrm{mL})$ and penicillin $(100 \mathrm{U} / \mathrm{mL})$. Then cells were incubated at $37{ }^{\circ} \mathrm{C}$ with $5 \% \mathrm{CO}_{2}$ and $95 \%$ air in humidified atmosphere.

\section{Cell proliferation assay}

MCF-7 cells were harvested and seeded into 96well plates at the concentration of $1 \times 10^{5}$ cells $/ \mathrm{mL}$, and incubated for $12 \mathrm{~h}$ at $37^{\circ} \mathrm{C}$. Then the cells were treated with different concentrations of $\operatorname{PTM}(0,25,50,100,200$ and $400 \mu \mathrm{g} / \mathrm{mL}$ for $24 \mathrm{~h}$ ) and also incubated for different time points at the concentration of 200 $\mu \mathrm{g} / \mathrm{mL}$ for 12,24 and $48 \mathrm{~h}$. At the end of the cultivation, cells were treated with $20 \mu \mathrm{L}$ MTT (5 $\mathrm{mg} / \mathrm{mL}$ ) in each well and then incubated for $4 \mathrm{~h}$ $\left(37^{\circ} \mathrm{C}\right)$. Then DMSO $(100 \mu \mathrm{L})$ were added in each well to dissolve the formazan crystals. The 
absorbance was measured using a microtiter plate reader (Bio-Rad Laboratories, CA, USA) at $570 \mathrm{~nm}$. The cell viability was calculated as the percent values compared with the control group.

\section{Western blot analysis}

After the indicated treatments, MCF-7 cells were collected and the protein was extracted. Equal amounts of $30 \mu \mathrm{g}$ solubilized proteins were separated on $12 \%$ SDS-PAGE and then transferred to PVDF membranes. The membranes were blocked with $5 \%$ skimmed milk, and then incubated with primary antibodies overnight at $4{ }^{\circ} \mathrm{C}$. Subsequently, the membranes were incubated with corresponding HRP conjugated secondary antibodies. Detection of proteins was carried out using a Bio-Rad enhanced chemiluminescence detection system (Bio-Rad Laboratories, Hercules, CA).

\section{Animals and in vivo tumor xenograft study}

Female BALB/c nude mice (18 - $22 \mathrm{~g})$ were obtained from Shandong Laboratory animal center (Ji'nan, China). Animals were maintained in a specific pathogen-free (SPF) environment $\left(21 \pm 2{ }^{\circ} \mathrm{C}\right.$ and $55 \pm 5 \%$ humidity) under a $12 \mathrm{~h}$ light/12 $\mathrm{h}$ dark cycle. The feed and water were supplied ad libitum. All experiments were carried out in accordance with "Principles of Laboratory Animal Care" (NIH publication no. 85-23, revised 1985) [10] and approved by Animal Ethics Committee of Qilu Hospital (approval no. ERK/2016/32).

Breast cancer xenograft models were established by subcutaneously injecting MCF-7 cells $\left(5 \times 10^{6}\right.$ /mouse) into the right flank of the nude mice. When the tumors reached about 100 $\mathrm{mm}^{3}$, the mice were randomly divided into 5 groups $(n=10)$ : positive group (capecitabine, 60 $\mathrm{mg} / \mathrm{kg}$ ), negative group (0.9\% saline) and three PTM groups (20, 40 and $60 \mathrm{mg} / \mathrm{kg}$ ). All groups were treated by intragastric administration for 21 days. Micrometer calipers were used to measure tumor sizes were every 3 days. Tumor volume was calculated using the formula as follows: $\mathrm{V}=$ $\left(\right.$ length $\times$ width $^{2}$ ) /2. At the end of the experiment, the mice were sacrificed, and the tumor were segregated and measured.

\section{Data analysis}

All data are presented as mean \pm standard deviation ( $S D, n=3$ ) and were evaluated by oneway analysis of variance (ANOVA). $P<0.05$ was considered to be statistically significant. RSM data were analyzed by Design-Expert trial version 8.0.5 (Stat-Ease Inc, Minneapolis, USA).

\section{RESULTS}

\section{Model fitting}

The effects of three variables (extraction temperature, liquid-solid ratio and extraction time) on the yields of PTM were examined using the BBD design. The complete design matrix together with the response values was shown in Table 1. The yield of PTM were $3.12 \%-4.65 \%$, and reached maximum with the extraction temperature of $60^{\circ} \mathrm{C}$, liquid-solid ratio of $18 \mathrm{~mL} / \mathrm{g}$ and extraction time of $40 \mathrm{~min}$. The response variable (yield) and the test variables (extraction temperature, liquid-solid ratio and extraction time) can be related by the following equation (Eq 2).

Yield $(\%)=4.53+0.46 \mathrm{~A}+0.27 \mathrm{~B}+0.27 \mathrm{C}+$ $0.13 A B+0.043 A C+0.045 B C-0.3 A^{2}-0.39$ $B^{2}-0.3 C^{2}$

The results of statistical analysis indicated that the established model was highly significant $(p<$ $0.0001, F=573.3965)$. The model showed a good fit with the high $R^{2}$ value of 0.9986 and adjusted determination coefficient $\left(R^{2}{ }_{\text {adj }}\right)$ of 0.9969 . The C.V. was 0.7652 , indicating that the experimental values were of a high degree of precision and a good deal of reliability. In addition, the independent variables of $A, B$ and $C$, the interaction terms of $A B, A C$ and $B C$, and all two quadratic terms $A^{2}, B^{2}$, and $C^{2}$, significantly affected the yield of PTM $(p<0.05)$.

\section{Optimization of extraction conditions}

The response surface plots and contour plots are shown in Fig. 2. One variable kept constant at middle level while the other two variables within experimental range were depicted in one response surface plot. It has been reported that the shapes of the contour plots were circular or elliptical, indicating the mutual interactions between the variables were significant or not [11]. The results in Fig 2 indicate that the interactions between the test variables were significant and the optimal extraction conditions by Design-Expert software were: extraction temperature of $58.17{ }^{\circ} \mathrm{C}$, liquid-solid ratio of $15.03 \mathrm{~mL} / \mathrm{g}$ and extraction time of $44.12 \mathrm{~min}$. The predicted yield of PTM at the optimal extraction condition was $4.84 \%$. 
Table 1: BBD and the response values for PTM yield

\begin{tabular}{lcccc}
\hline Run & $\begin{array}{c}\text { A: Extraction temperature } \\
\left({ }^{\circ} \mathbf{C}\right)\end{array}$ & $\begin{array}{c}\text { B: Liquid-solid ratio } \\
(\mathbf{m L} / \mathbf{g})\end{array}$ & C: Extraction time (min) & Yield (\%) \\
\hline 1 & 40.00 & 18.00 & 40.00 & 3.47 \\
2 & 50.00 & 12.00 & 40.00 & 4.53 \\
3 & 40.00 & 12.00 & 50.00 & 3.59 \\
4 & 60.00 & 12.00 & 50.00 & 4.58 \\
5 & 40.00 & 6.00 & 40.00 & 3.23 \\
6 & 40.00 & 12.00 & 30.00 & 3.12 \\
7 & 50.00 & 18.00 & 30.00 & 3.73 \\
8 & 50.00 & 12.00 & 40.00 & 4.55 \\
9 & 60.00 & 12.00 & 30.00 & 3.94 \\
10 & 50.00 & 6.00 & 50.00 & 3.67 \\
11 & 60.00 & 6.00 & 40.00 & 3.88 \\
12 & 50.00 & 12.00 & 40.00 & 4.54 \\
13 & 50.00 & 6.00 & 30.00 & 3.25 \\
14 & 50.00 & 12.00 & 40.00 & 4.48 \\
15 & 50.00 & 12.00 & 40.00 & 4.55 \\
17 & 50.00 & 18.00 & 50.00 & 4.33 \\
\hline
\end{tabular}
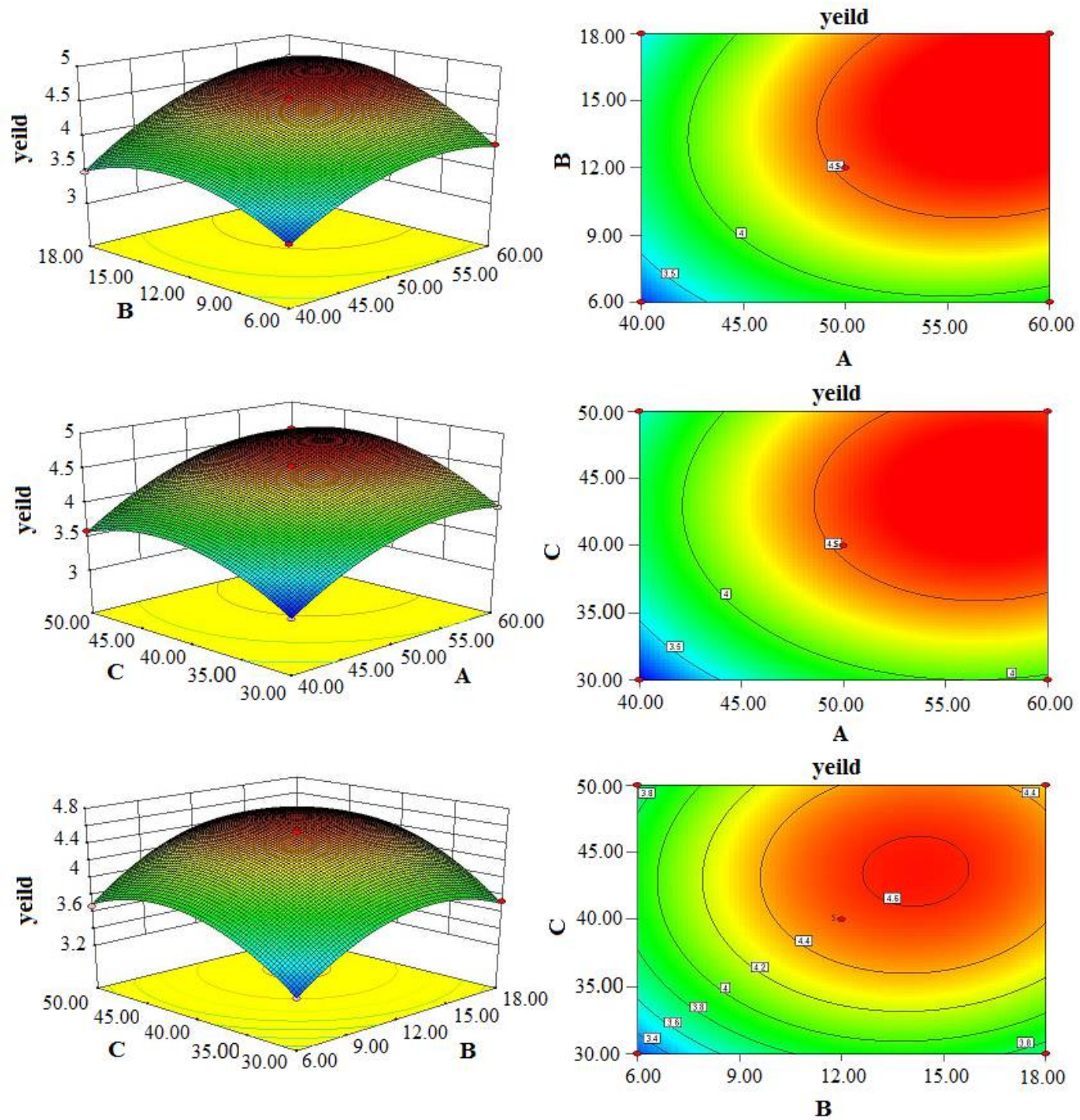

Figure 1: Response surface and contour plots showing the effects of variables and their mutual effects on the extraction yield of PTM 


\section{Validation of the models}

To validate the adequacy of the model, a verification experiment was performed under the following conditions: extraction temperature of $58.2{ }^{\circ} \mathrm{C}$, liquid-solid ratio of $15 \mathrm{~mL} / \mathrm{g}$ and extraction time of $44.12 \mathrm{~min}$. Under these conditions, the yield of PTM was $4.86 \pm 0.13 \%$. The results indicated that the RSM was effective and appropriate for optimizing the conditions for extracting PTM.

\section{PTM inhibited the viability of MCF-7 cells}

MTT assay was performed to study the inhibitory effects of PTM on MCF-7 cells in the present study. As shown in Figure 2A, PTM inhibited the viability of MCF-7 cells at the concentrations of $50,100,200$ and $400 \mu \mathrm{g} / \mathrm{mL}$ in concentrationdependent manners. The relationship between the inhibitory effect and time was also investigated within $48 \mathrm{~h}$, and the results showed that PTM inhibited the viability of MCF-7 cells in time-dependent manners (Figure 2B).

\section{Expression of p53, Bax and Bcl-2 proteins}

The expression of apoptosis regulatory proteins were examined to study the effect of PTM on MCF-7 cells apoptosis. As can be seen from Figure 3, the expression of pro-apoptotic proteins p53 and Bax were significantly upregulated by treating with PTM compared with control cells at the concentrations of 100,200 and $400 \mu \mathrm{g} / \mathrm{mL}$. Furthermore, the expression of anti-poptotic protein $\mathrm{Bcl}-2$ was significantly down-regulated after treatment of PTM compared with cells in the control group at the tested concentrations.

\section{PTM suppressed tumor growth in mouse}

From Figure 4, the results showed that the tumor growth inhibitory effects were increased with the dose increase of PTM. The treatment of PTM significantly reduced the tumor volume at the doses of 20,40 and $80 \mathrm{mg} / \mathrm{kg}$ compared with the control group $(p<0.01)$. The tumor weights of PTM-treated mice $(20,40$ and $80 \mathrm{mg} / \mathrm{kg}$ ) were also significantly less than that of the control group $(p<0.01)$.
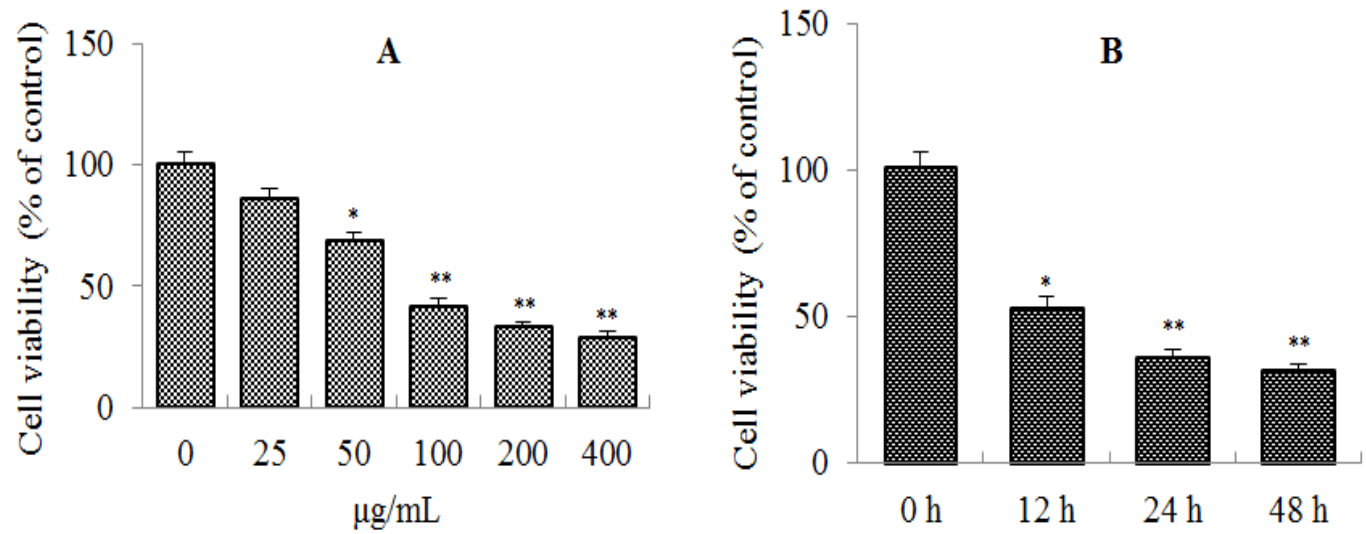

Figure 2: Effect of PTM on the proliferation of MCF-7 cells

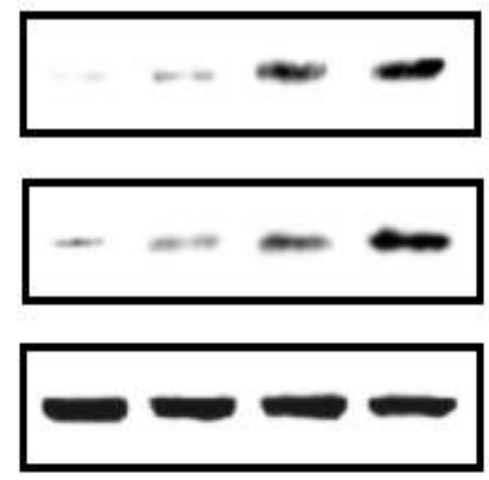

p53

Bax

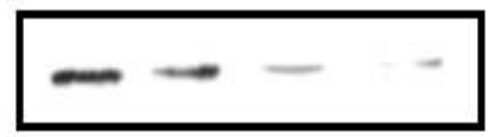

Bcl-2

$\beta$-Actin

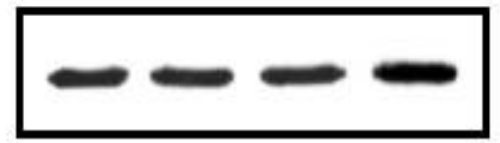

$\beta$-Actin

Control $\quad 100 \quad 200 \quad 400 \quad \mu \mathrm{g} / \mathrm{mL}$

Control $\quad 100 \quad 200 \quad 400 \quad \mu \mathrm{g} / \mathrm{mL}$

Figure 3: p53, Bax and Bcl-2 protein expression in MCF7 cells treated with PTM 

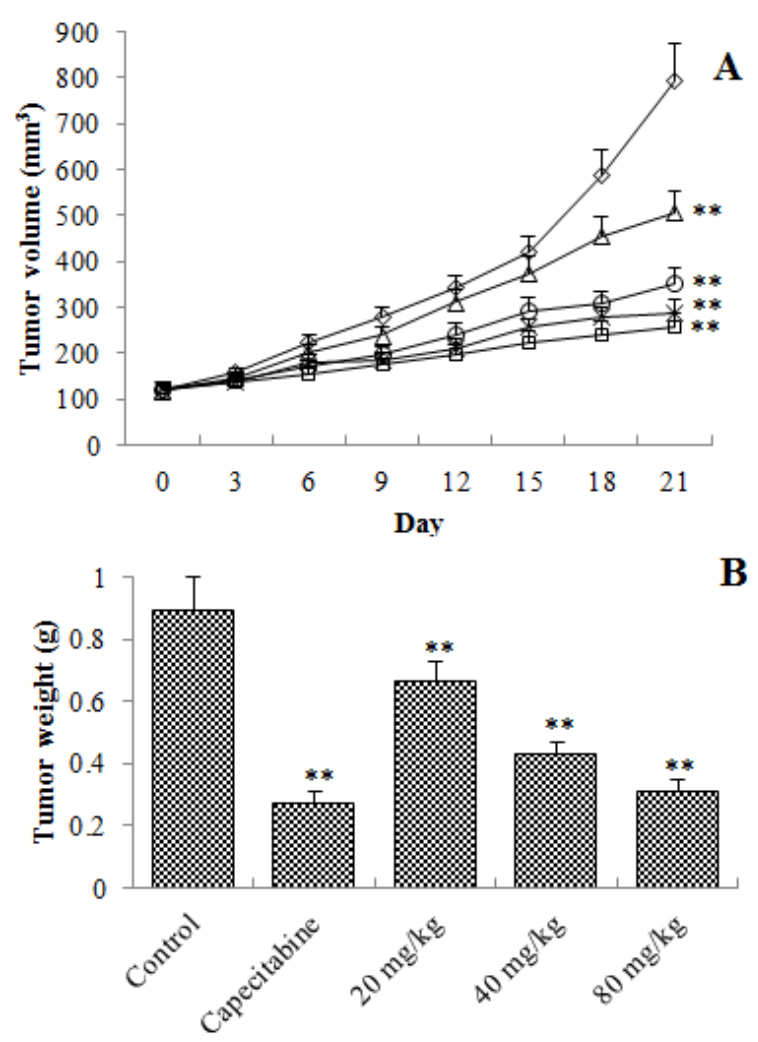

Figure 4: The effects of PTM treatment on MCF-7 cells in vivo. (A) Tumor volume, measured once every 3 days; (B) Tumor mass weight; $\diamond$ control, $\square$ Capecitabine, $\circ 40 \mathrm{mg} / \mathrm{kg}, \Delta 20 \mathrm{mg} / \mathrm{kg}, \times 80 \mathrm{mg} / \mathrm{kg}$

\section{DISCUSSION}

Ultrasonic extraction is a new technology that attracts much attention in the extraction of natural products and it is considered as one of the most inexpensive, simple and efficient techniques [12]. Response surface methodology (RSM) is an effective model for optimizing complex processes, and it saves more labor and time than other methods [13]. RSM is easy to carry out, and it has already been applied to optimize the extraction conditions of polysaccharide in previous researches $[14,15]$.

Ultrasonic extraction technique was used in the present study for extracting PTM and the related conditions of extraction were optimized by BBD. As a result, the optimal extraction conditions for PTM were obtained, and the validation experiments indicated that the RSM was effective.

Apoptosis is the process of programmed cell death and it is very important in the control of cell development and proliferation [16]. Apoptosis may result in abnormal expression of $\mathrm{Bcl}-2$ family members including Bcl-2 and Bax, which are key regulators of cell apoptosis and play pivotal roles in anti-apoptotic and pro-apoptotic, respectively [17]. Furthermore, p53 is a very important tumor suppressor protein that mediates the stressinduced apoptosis cascade [18,19].

In this study, a significant decrease of $\mathrm{Bcl}-2$ expression and a marked increase of Bax and p53 expression were observed in MCF-7 cells after treating with PTM. Therefore, the results indicate that the anti-tumor effect of PTM is closely associated with induction of apoptosis.

The present study showed that polysaccharides from $T$. mongolicum can inhibit the growth of MCF-7 cells in vitro and in vivo. Thus, polysaccharides might be one of the effective components of $T$. mongolicum for the treatment of mastopathy.

\section{CONCLUSION}

RSM has been shown to be effective for optimizing the extraction conditions of PTM by ultrasonic extraction. PTM possesses significant anti-tumor effect on MCF-7 cells in vitro and in vivo by inducing apoptosis. Thus, PTM have the potential to develop into anti-tumor drugs for the treatment of breast cancer in the future.

\section{DECLARATIONS}

\section{Conflict of Interest}

No conflict of interest associated with this work.

\section{Contribution of Authors}

The authors declare that this work was done by the authors named in this article and all liabilities pertaining to claims relating to the content of this article will be borne by them.

\section{Open Access}

This is an Open Access article that uses a funding model which does not charge readers or their institutions for access and distributed under the terms of the Creative Commons Attribution License (http://creativecommons.org/licenses/by 14.0) and the Budapest Open Access Initiative (http://www.budapestopenaccessinitiative.org/rea d), which permit unrestricted use, distribution, and reproduction in any medium, provided the original work is properly credited.

\section{REFERENCES}

1. Park JY, Shin MS, Kim SN, Kim HY, Kim KH, Shin KS, 
Kang KS. Polysaccharides from Korean Citrus hallabong peels inhibit angiogenesis and breast cancer cell migration. Int J Biol Macromol 2016; 85: 522-229.

2. Dubey AK, Gupta U, Jain S. Breast cancer statistics and prediction methodology: a systematic review and analysis. Asian Pac J Cancer Prev 2015; 16(10): 42374245.

3. Zeng $H$, Zheng $R$, Zhang $S$, Zou X, Chen W. Female breast cancer statistics of 2010 in China: estimates based on data from 145 population-based cancer registries. J Thorac Dis 2014; 6(5): 466-470.

4. Majeed W, Aslam B, Javed I, Khaliq T, Muhammad F, All A, Raza A. Breast cancer: major risk factors and recent developments in treatment. Asian Pac J Cancer Prev 2014; 15(8): 3353-3358.

5. Wu J, Yang C, Guo C, Li X, Yang N, Zhao L, Hang $H$, Liu $S$, Chu $P$, Sun $Z$, et al. SZC015, a synthetic oleanolic acid derivative, induces both apoptosis and autophagy in MCF-7 breast cancer cells. Chem Biol Interact 2016; 244: 94-104.

6. Lee JS, Synytsya A, Kim HB, Choi DJ, Lee S, Lee J, Kim WJ, Jang S, Park YI. Purification, characterization and immunomodulating activity of a pectic polysaccharide isolated from Korean mulberry fruit Oddi (Morus alba L.). Int Immunopharmacol 2013; 17(3): 858-866.

7. Ji YB, Dong F, Ma DB, Miao J, Jin LN, Liu ZF, Zhang LW. Optimizing the extraction of anti-tumor polysaccharides from the fruit of Capparis spionosa $L$. by response surface methodology. Molecules 2012; 17(6): 7323 7335.

8. Shi S, Zhang Y, Zhao Y, Huang K. Preparative isolation and purification of three flavonoid glycosides from Taraxacum mongolicum by high-speed counter-current chromatography. J Sep Sci 2008; 31(4): 683-688.

9. Wang $X$, Li $F$, Sun $Q$, Yuan J, Jiang $T$, Zheng $C$. Application of preparative high-speed counter-current chromatography for separation and purification of arctiin from Fructus Arctii. J Chromatogr A 2005; 1063(1-2): 247-251.

10. "Principles of Laboratory Animal Care" (NIH publication no. 85-23, revised 1985). Available from: http://grants 1.nih.gov/grants/olaw/references/phspol.htm

11. Ye $H$, Jin $Y$, Lin $S$, Liu $M$, Yang $Y$, Zhang $M$, Zhao $P$, Jones $G$. Effect of pulsed electric fields on the activity of neutral trehalase from beer yeast and RSM analysis. Int J Biol Macromol 2012; 50(5): 1315-1321.

12. Jiang $C$, Li $X$, Jiao $Y$, Jiang $D$, Zhang $L$, Fan $B$, Zhang $Q$. Optimization for ultrasound-assisted extraction of polysaccharides with antioxidant activity in vitro from the aerial root of Ficus microcarpa. Carbohydr Polym 2014; 110: 10-17.

13. Chen J, Zhang $T$, Jiang $B$, Mu $W$, Miao $M$. Characterization and antioxidant activity of Ginkgo biloba exocarp polysaccharides 2012; 87(1): 40-45.

14. Chen $Y$, Yin L, Zhang $X$, Wang $Y$, Chen $Q$, Jin $C, H u Y$, Wang J. Optimization of alkaline extraction and bioactivities of polysaccharides from rhizome of Polygonatum odoratum. Biomed Res Int 2014; 2014: 504896.

15. Ji YB, Dong F, Ma DB, Miao J, Jin LN, Liu ZF, Zhang $L W$. Optimizing the extraction of anti-tumor polysaccharides from the fruit of Capparis spionosa $L$. by response surface methodology. Molecules 2012; 17(6):73237335.

16. Thompson C B. Apoptosis in the pathogenesis and treatment of disease. Science 1995; 267(5203): 14561462.

17. Chipuk JE, Kuwana T, Bouchier-Hayes L, Droin NM, Newmeyer DD, Schuler M, Green DR. Direct activation of Bax by p53 mediates mitochondrial membrane permeabilization and apoptosis. Science 2004; 303(5660): 1010-1014.

18. Guo $W$, Zhang $Y$, Ling $Z$, Liu $X$, Zhao $X$, Yuan $Z$, Nie $C$, Wei $Y$. Caspase-3 feedback loop enhances Bid-induced AIF/endoG and Bak activation in Bax and p53independent manner. Cell Death Dis 2015; 6: e1919.

19. Saha S, Hossain DM, Mukherjee $S$, Mohanty $S$, Mazumdar M, Mukherjee S, Ghosh UK, Nayek $C$, Raveendar C, Khurana $A$, et al. Calcarea carbonica induces apoptosis in cancer cells in p53-dependent manner via an immuno-modulatory circuit. BMC Complement Altern Med 2013; 13: 230. 